\title{
Experimental and modeling study of fuel interactions with an alkyl nitrate cetane enhancer, 2-ethyl-hexyl nitrate
}

\author{
S.S. Goldsborough ${ }^{1,2}$ \\ M.V. Johnson ${ }^{1}$ \\ C. Banyon ${ }^{1}$ \\ W.J. Pitz ${ }^{3}$ \\ M. McNenly ${ }^{3}$ \\ ${ }^{1}$ Energy Systems Division, Argonne National Laboratory, Argonne, IL 60439, USA \\ ${ }^{2}$ Department of Mechanical and Industrial Engineering, University of Illinois Chicago, Chicago, IL 60607, USA \\ ${ }^{3}$ Lawrence Livermore National Laboratory, Livermore, CA, 94551, USA
}

Corresponding author:

S. Scott Goldsborough

Energy Systems Division

Argonne National Laboratory

9700 S. Cass Avenue

Argonne, IL 60439

USA

Email: scott.goldsborough@anl.gov

Phone: +1-630-252-9375

Fax: +1-630-252-3443

Colloquium:

Reaction Kinetics

Alternate: IC Engine and Gas Turbine Combustion

Total length:

Total: 6198

Word Equivalent Lengths (Method 1):

Main Text: 4531

Equations: 23

Nomenclature: 0

References: 664

Tables: 0

Figures and Captions: 980

Total: 6198

(C) 2014. This manuscript version is made available under the Elsevier user license 


\section{Abstract}

This study investigates the autoignition behavior of two gasoline surrogates doped with an alkyl nitrate cetane enhancer, 2-ethy-hexyl nitrate (2EHN) to better understand dopant interactions with the fuels, including influences of accelerating kinetic pathways and enhanced exothermicity. A primary reference fuel (PRF) blend of $n$-heptane/iso-octane, and a toluene reference fuel (TRF) blend of $n$-heptane/iso-octane/toluene are used where the aromatic fraction of the latter is set to $20 \%$ (liquid volume), while the content of $n$-heptane is adjusted so that the overall reactivity of the undoped fuels is similar, e.g., Anti-Knock Index (AKI) of 91, Cetane Number $(\mathrm{CN}) \sim 25$. Doping levels of $0.1,1.0$ and 3.0\% (liquid volume basis) are used where tests are conducted within a rapid compression machine (RCM) at a compressed pressure of 21 bar, covering temperatures from 675 to $1025 \mathrm{~K}$ with stoichiometric fuel-oxygen ratios at $\mathrm{O}_{2}=11.4 \%$.

At the experimental conditions, it is found that the doping effectiveness of $2 \mathrm{EHN}$ is fairly similar between the two fuels, though $2 \mathrm{EHN}$ is more effective in the aromatic blend at the lowest temperatures, while it is slightly more effective in the non-aromatic blend at intermediate temperatures. Kinetic modeling of the experiments indicates that although some of the reactivity trends can be captured using a detailed model, the extents of predicted Cetane Number enhancement by 2EHN are too large, while differences in fuel interactions for the two fuels results in excessive stimulation of the non-aromatic blend. Sensitivity analysis using the kinetic model indicates that the $\mathrm{CH}_{2} \mathrm{O}$ and $\mathrm{CH}_{3} \mathrm{O}_{2}$ chemistry are very sensitive to the dopant at all conditions. The rate of $2 \mathrm{EHN}$ decomposition is only important at low temperatures where its decomposition rate is slow due to the high activation energy of the reaction. At higher temperatures, dopant-derived 3-heptyl radicals are predicted to play an important role stimulating ignition. Finally, nitrogen chemistry becomes important only at the highest doping levels, primarily through the formation of methyl and ethyl nitrite, and nitric acid.

\section{Key Words:}

rapid compression machine, cetane enhancer, alkyl nitrates, fuel interactions 


\subsection{Introduction}

Alkyl nitrates are identified as effective fuel additives which can be used in very small quantities (e.g., 1 to $1000 \mathrm{ppm}$ ) to improve the ignition quality of 'low grade' fuels. Ignition quality is often designated using Cetane Number $(\mathrm{CN})$ where high values, e.g., $\mathrm{CN}>60$, indicate very reactive fuels, such as those with significant amounts of linear paraffins, while low values, e.g., $\mathrm{CN}<30$, indicate less reactive fuels, such as ones with high iso-paraffinic or aromatic content. Low fuel reactivity can lead to problems in diesel combustion concerning power output, engine deposits, high emissions, rough operation, and cold starting. Fuel reactivity has also been identified as an important parameter influencing the performance and controllability of advanced combustion schemes, such as homogeneous charge compression ignition (HCCI) [1] and reactivity controlled compression ignition ( $\mathrm{RCCl}$ [2]. It has been suggested that fuel additives could be one way to dynamically control fuel reactivity during engine operation in order to cover a wide range of combustion modes.

Alkyl nitrates, and other cetane enhancers such as peroxides, e.g., di-tert-butyl peroxide (DTBP), are highly reactive compounds containing weak intramolecular bonds which lead to rapid decomposition at modest temperatures. This means that in practical combustors they break down early in the combustion process. Decomposition yields active chemical species; in the case of alkyl nitrates, alkyl radicals, aldehydes and nitrogen dioxide are formed. These products interact with the fuel and other gases, e.g., $\mathrm{O}_{2}$, to accelerate the ignition process. The early reactions often have some exothermicity and thus can provide a thermal stimulant to supplement the accelerating kinetic pathways. Alkyl nitrates are advantageous due to their low cost and chemical stability outside of the combustion chamber. Peroxides, for instance, can react with the fuel during storage resulting in increased rates of gum, varnish and sediment formation during engine operation.

Alkyl nitrates and peroxides have been investigated in fundamental experiments, as well as combustion engines, while a number of detailed theoretical and modeling studies have also been undertaken [3-17]. Singleshot spray chambers have been used [3], as have RCMs [4-6], shock tubes [7-8] and flow reactors [9]. Engine studies have utilized conventional and low temperature combustion (LTC) direct injection schemes [10-12], as 
well as $\mathrm{HCCl}$ [13] and RCCI [14-15]. Chemical kinetic models have been developed to predict the decomposition behavior of 2EHN and DTBP [5, 16-17], and the sensitizing effects they have on some fuels of interest, e.g., nheptane [8].

Currently however, there is still a lack of fundamental understanding regarding a number of issues related to fuel additives, including:

1. How do additives interact with fuel components (e.g., paraffins, branched alkanes, aromatics, olefins, etc.) across a range of engine operating conditions?

2. What are the influences of exothermicity and accelerating kinetic pathways?

3. Can interactions and influences be reliably predicted, along with impacts to pollutant formation?

4. Are there optimal additives that can be used across a range of operating modes, including LTC?

The objective of this study is to provide insight into these questions. Experiments and modeling are conducted where tests are performed using an RCM. Two different gasoline surrogates are used in order to discern the influence of aromatic content on the effectiveness of $2 \mathrm{EHN}$, while the overall level of reactivity is similar. Gasoline surrogates are employed here as opposed to diesel ones due to the relevance of gasoline to some LTC modes [12] as well as single-fuel RCCI [14-15] where cetane enhancers are of interest, while a relevant range of doping levels is explored. Chemical kinetic models are developed and simulations conducted of the RCM experiments. Sensitivity and rate-of-production (ROP) analyses are also performed to facilitate an understanding of the mechanistic interactions.

The rest of this paper is organized as follows. First, the experimental facilities and techniques are described, after which the kinetic model and simulation framework are discussed. The results are then presented, followed by a summary and conclusions of the current work.

\subsection{Experimental}

Argonne's twin, opposed-piston RCM is used for this study. Its capabilities are detailed elsewhere [18], however a brief description is provided here. The reaction chamber (RC) has a $50.8 \mathrm{~mm}$ bore with a clearance 
height at maximum compression of $26.5 \mathrm{~mm}$. Creviced pistons are employed to minimize fluid dynamic effects during compression and improve post-compression charge homogeneity. The crevice volume fraction is $\sim 14 \%$ of the RC volume. Hydraulic pistons are used to actuate compression and lock the pistons at TDC. Compression times are typically less than 20 ms. For this work, the geometric compression ratio (CR) is maintained at 14.3:1, while the effective compression ratio, which accounts for heat loss, is 10.2:1.

Pressure histories are measured using a Kistler 601A transducer mounted flush in the RC side wall. The transducer output is conditioned by a Kistler SCP-Slim amplifier (Model 2852A12) with the data captured at 20 $\mathrm{kHz}$. To minimize thermal shock effects, the diaphragm is coated with a $0.75 \mathrm{~mm}$ thick layer of Momentive TSE399 RTV silicon. Minimal loss in sensitivity and thus determination of the compressed conditions and ignition delay times $(\tau)$ are verified by comparing pressure rise rates during compression with data acquired using the uncoated transducer.

Liquid blends of PRF91 and TRF91 surrogates + 2EHN are prepared gravimetrically, with a relative error in doping level of $\pm 1 \%$. To prepare the test mixtures, the liquid fuels are injected directly into an external $5.6 \mathrm{~L}$, stainless steel mixing vessel, while the gases are manometrically delivered. An Omega PX419-100A5V transducer is used to measure the partial pressures, with relative errors in the resulting equivalence ratio $(\phi)$ and $\% \mathrm{O}_{2}$ of $\pm 3 \%$. The mixing vessel is heated to $35 \mathrm{C}( \pm 5 \mathrm{C})$ to promote fuel vaporization and the complete mixture is allowed a 120 minute period to diffusively homogenize before use. For the highest doping levels the tank is heated to $50 \mathrm{C}$ to ensure complete vaporization of the additive. Test gases are metered through a heated supply line into the evacuated RC until the prescribed initial pressure $\left(\mathrm{P}_{0}\right)$ is reached, where an Omega PX01C1050Al transducer $( \pm 0.17 \mathrm{kPa})$ is used. The RC temperature is varied using a resistive heating element wrapped around the exterior of the chamber and cylinders, and controlled by a Yokogawa UP350E PID controller. A 30 minute period is used with each temperature change to ensure thermal equilibration. After introduction into the $\mathrm{RC}$, the test gas is allowed to heat and homogenize for at least 7 minutes to minimize pre-test thermal stratification and decrease variability in the experiments. This is found to be especially important for the highly doped mixtures where spurious preignition heat release is observed during tests using shorter wait times. To 
improve data fidelity, the RC is frequently disassembled and cleaned. The interior walls are washed with acetone, and the reassembled RCM is placed under low vacuum, and heated to $120 \mathrm{C}$ for 1 hour to remove any remaining contaminants. The mixing vessel is purged with inert gas, heated to $65 \mathrm{C}$ and placed under low vacuum for 1 hour to evacuate the volume.

In the current study, high purity (99.99\%) nitrogen, argon, and oxygen are used which were supplied by Airgas. The liquid fuels include: iso-octane (99.8\%, Sigma-Aldrich), $n$-heptane (99+\%, Acros Organics), toluene (99.8\%, Sigma-Aldrich), and 2-ethyl-hexyl nitrate (97\%, Sigma-Aldrich). The undoped TRF blend has an aromatic content of $20 \%$ (by liquid volume) with the $n$-paraffinic content adjusted to $12.8 \%$ achieve AKI near 91 (CN 25). All mixtures use stoichiometric fuel-oxygen conditions, with the oxygen mole fraction set to $11.4 \%$. The diluent for these tests is either pure nitrogen, or a blend of $0.25 / 0.75$ nitrogen/argon. Significant dilution is used here to account for the substantial cetane enhancement of the doped fuels where very short ignition delay times result. $2 \mathrm{EHN}$ doping levels are $0.0,0.1,1.0$ and $3.0 \%$ liquid volume basis. The highest temperatures are not covered in these tests for the 3.0\% doping level due to the fuel's excessive reactivity.

The compressed temperatures are achieved by varying the initial temperature $\left(T_{0}\right)$, from 25 to $100 \mathrm{C}$, as well as the diluent composition. $P_{0}$ is adjusted slightly to achieve 21 bar ( \pm 0.3 bar) compressed pressures (Pc). Two tests are conducted at each condition to ensure repeatability, with typical ignition delay time variations near $\pm 1-2 \mathrm{~ms}$. The compressed temperatures (Tc) are calculated using the adiabatic core model, along with the measured pressure histories. The specific heat ratios are determined via $c_{p}$ fits in the CHEMKIN database. Before calculating the temperatures, the pressure records are smoothed using a Savitzky-Golay algorithm that employs a $3^{\text {rd }}$ order polynomial with a window of 20 data points.

For this study, comparisons are made using Tc of the undoped fuel mixtures, since many of the doped mixtures experience heat release during the piston compression process, as discussed in the Results section. Ignition delay times, $\tau$, are defined as the time from the end of compression to the point of rapid pressure rise associated with the main heat release. In the case of two stage ignition, $1^{\text {st }}$ stage ignition is defined as the time from end of compression to the first distinguishable pressure rise, i.e., a peak in $\mathrm{dP} / \mathrm{dt}$. The end of compression 
is defined by the peak in pressure for a non-reactive, undoped mixture, i.e., with $\mathrm{O}_{2}$ replaced by $\mathrm{N}_{2}$, where the reactive tests are time-shifted to in order correspond with the non-reactive pressure trace, such that the reactive and non-reactive pressures are assumed to be equal at a CR of $4: 1$. This procedure is undertaken to reduce measurement uncertainties for conditions where substantial heat release occurs during compression, and results in some variability, e.g., $\pm 0.25 \mathrm{~ms}$, in the measured delay times, but ensures consistency between all of the tests. Ignition delay times shorter than $1 \mathrm{~ms}$ are discarded. Compiled ignition times are provided in the Supplementary Material.

\subsection{Modeling}

Two kinetic models are used here which consist of a base fuel mechanism, a sub-mechanism for the additive, and a sub-mechanism for the nitrogen chemistry. The fuel mechanism is the Lawrence Livermore National Laboratory (LLNL) detailed gasoline surrogate model, which includes decomposition and interaction pathways for four fuel components including n-heptane, iso-octane, toluene and pentene [19-21]. The submechanism for the additive, 2EHN, is based on the work of Bornemann et al. [17]. In this 2EHN decomposes in two steps. First, the interior $\mathrm{O}-\mathrm{N}$ bond is cleaved to release $\mathrm{NO}_{2}$; after this the ethyl-hexyloxy radical $\beta$-scissions into $\mathrm{C}_{7} \mathrm{H}_{15}-3$ and $\mathrm{CH}_{2} \mathrm{O}$.

Two sub-mechanisms for nitrogen chemistry are explored here, one which is a skeletal compilation and includes basic pathways for the formation and consumption of $\mathrm{NO}, \mathrm{N}_{2} \mathrm{O}$ and $\mathrm{NO}_{2}, \mathrm{H}$-atom abstractions from the surrogate fuel by $\mathrm{NO}_{2}$, and $\mathrm{HONO}$ decomposition [8]. A comprehensive, detailed mechanism is also assembled that includes pathways described in GRIMech 3.0 [22], Dagaut and co-workers [23-26], Glarborg and co-workers [27-28] Faravelli and co-workers [29], Battin-Leclerc and co-workers [30], and Naik and co-workers [31]. In particular, reactions are included to describe interactions with nitrous and nitric acid $\left(\mathrm{HONO}, \mathrm{HONO}_{2}\right)$, hydrogen cyanide $(\mathrm{HCN})$ and others, along with various fuel-specific interactions. NOx reactions with fuel-derived molecules $(\mathrm{RH})$ are summarized as follows: $\mathrm{RH}+\mathrm{NO}=\mathrm{R}+\mathrm{HNO}, \mathrm{RH}+\mathrm{NO}_{2}=\mathrm{R}+\mathrm{HONO}, \mathrm{R}+\mathrm{NO}=\mathrm{olefin}+\mathrm{HNO}, \mathrm{R}+\mathrm{NO}=\mathrm{RNO}$,

$\mathrm{R}+\mathrm{NO}_{2}=\mathrm{RNO}_{2}, \quad \mathrm{RO}+\mathrm{NO}=\mathrm{RO}+\mathrm{NO}_{2}, \quad \mathrm{RO} \mathrm{N}_{2}+\mathrm{NO}=\mathrm{RONO}_{2}, \quad \mathrm{RO}+\mathrm{NO}=\mathrm{R}^{\prime} \mathrm{O}+\mathrm{HNO}, \quad \mathrm{RO}+\mathrm{NO}_{2}=\mathrm{RONO}_{2}$ 
$\mathrm{RNO}+$ radical=olefin $+\mathrm{NO}+$ radical, $\mathrm{RNO}_{2}+$ radical=olefin $+\mathrm{NO}_{2}+$ radical, $\mathrm{RONO}_{2}=\mathrm{R}^{\prime} \mathrm{O}+\mathrm{HONO}, \mathrm{RONO}_{2}+\mathrm{OH}=\mathrm{RO}+\mathrm{HONO}_{2}$. Many of these have not been considered in previous combustion models. New rate constants are based on analogous small molecule reactions, while new thermochemistry is computed using the THERM software [32]. Uncertainties associated these additional species are not considered significant since the model exhibits little sensitivity in $\tau$ to the detailed fuel-specific interactions at the conditions explored here. More details of the extended NOx mechanism can be found in [18].

Simulations of the RCM experiments are conducted using CHEMKIN II where the adiabatic core hypothesis is employed. As per convention, empirical expressions that account for heat loss in the opposedpiston RCM are utilized where these are derived based on experiments using non-reactive mixtures [33]. An adiabatic, single-zone is utilized with time-varying volume where the calculations are initialized before the piston compression process starts and conducted to just after the point of main heat release, i.e., ignition. Effects of reactivity during compression are thus taken into account, where this is especially important for the doped mixtures, as discussed in the Results section. Small integration errors associated with the empirical piston trajectories are taken into account by slightly modifying the velocity profiles $( \pm 0.3 \%)$ and $P_{0}( \pm 2 \%)$ to achieve compressed conditions consistent with the experiments (differences less than $1 \%$ in Tc and Pc).

While this simulation approach has been successfully used in the past to model single-stage fuels in RCM experiments [33], it does not properly account for physical-chemical couplings that occur in RCMs due to reaction chamber - crevice interactions during multi-stage ignition events [34]. Unfortunately, a more physically realistic expression for the ANL RCM was not available for this study. This is a slight limitation of the current model where some uncertainties are introduced $(\sim 10-25 \%$ in $\tau)$. For a detailed discussion of the aspects of this the reader is referred to ref. [34].

A brute force, or local sensitivity analysis is also conducted at two representative temperatures, $\mathrm{T}=684$ $\mathrm{K}$ and $836 \mathrm{~K}$, with the other conditions, e.g., $\mathrm{Pc}, \phi$, consistent with the experiments. Only the "LLNL + detailed NOx" mechanism is considered here. For simplicity, these calculations assume an adiabatic, constant volume 
reactor. The forward and reverse A-factors for each of the $\mathrm{i}^{\text {th }}$ reactions are perturbed individually by a factor of 2 so that sensitivity coefficients can be calculated via

$S_{i}=\frac{d(\ln (\tau))}{d(\ln (k))}=\frac{k}{\tau} \frac{d(\tau)}{d(k)} \approx \frac{\ln \left(\tau_{2} / \tau_{1}\right)}{\ln \left(k_{2} / k_{1}\right)}$

where the subscripts " 1 " and " 2 " indicate perturbations about the base mechanism. While this approach does not capture interactions between reactions, or uncertainties in individual rate constants as a global sensitivity analysis would [35], it is straightforward to undertake and provides a fair indication of important reactions leading to fuel decomposition and ignition.

\subsection{Results}

The experimental and modeling results are presented as follows. First, the data and simulations of the experiments are discussed, with this followed by a review of the sensitivity and ROP analyses.

\subsection{Experimental conditions}

Figure 1 illustrates measured and computed ignition delay times for the two undoped gasoline surrogates, PRF91 and TRF91, covering temperatures from Tc $=675$ to $1025 \mathrm{~K}$. Also included in this figure for reference are ANL data for iso-octane-'air' mixtures (PRF100) conducted at $p=20$ bar, $\phi=1.0$ and 21\% $\mathrm{O}_{2}$; these are the RCM Workshop conditions [36] and are presented here to demonstrate the reliability of the current dataset. The data for the PRF91 and TRF91 mixtures can be seen to have measured ignition times that are much longer than the PRF100 mixture, where this is due to the high level of dilution used in the current experiments. Also visible in this figure is that while the LLNL mechanism reasonably predicts the $1^{\text {st }}$ and $2^{\text {nd }}$ stage ignition times for the PRF100 cases, the predictions are generally too fast for the undoped PRF91 and TRF91 mixtures. However, it should be noted that the differences in negative temperature coefficient (NTC) behavior between the two fuels that are seen in the experiments, e.g., the crossover point near $750 \mathrm{~K}$ and the slopes in the NTC region (where the TRF91 mixture is seen to be flatter which corresponds to its octane sensitivity), are 
adequately predicted by the detailed mechanism. The predictions for the PRF91 mixture are slightly better than for the TRF91 mixture.

Figure 2 presents representative pressure traces at a low temperature condition, $\mathrm{T}=710 \mathrm{~K}$, for the two fuels covering all of the doping conditions. It should be noted that some of the reactive data are shifted to match the non-reactive traces at a CR of 4:1 as noted earlier. Simulation results using the two mechanisms are included. Here, it can be seen that at these conditions, the experiments do not indicate that the dopant substantially alters the extents of heat release, or pressure / temperature rise during the $1^{\text {st }}$ stage of ignition, even for the highest doping level, though the timings of the $1^{\text {st }}$ stage are shifted considerably relative to the undoped mixtures. The modeling results indicate somewhat similar trends, but the $\tau$ shifts due to the $2 \mathrm{EHN}$ are noticeably different. Fairly comparable behavior is observed between the predictions using the detailed and the skeletal NOx models, but only at the lowest doping condition. As the doping fraction increases however, the influence of the detailed nitrogen chemistry becomes apparent. This is evident for both surrogate mixtures. This feature is consistent across most of the temperature range, as will be discussed. Also noticeable in Fig. 2 is that there appears to be more $1^{\text {st }}$ stage heat release / temperature rise in the simulations than in the measurements. Some of this discrepancy can be attributed to the simulation approach used here [34], but it is unclear how much. Additionally visible upon close inspection, though perhaps not with the resolution provided here, is that there is substantial reactivity during the compression stroke for the simulations, where this is also seen in some of the doped experiments.

Figures 3 and 4 summarize the experimental measurements for the PRF91 and TRF91 blends where an effectiveness ratio, defined as $R_{\text {eff }}=\tau_{\text {doped }} / \tau_{\text {undoped, }}$, is plotted as a function of the inverse temperature. Here the plots utilize Tc based on the undoped mixtures. $R_{\text {eff }}$ provides an indication of how influential $2 \mathrm{EHN}$ is in accelerating the reactivity of the mixture. A number of features are evident in these figures. First, the PRF91 and TRF91 mixtures exhibit very similar behavior, for the experiments and both of the models. There appears to be a peak in $R_{\text {eff }}$ near $740 \mathrm{~K}$ where the $2 \mathrm{EHN}$ has minimal influence. This is near the transition from low temperature to NTC chemistry for these fuels. On the lower temperature side of this peak there is not much 
difference in $\mathrm{R}_{\mathrm{eff}}$ between the three different doping levels. However, at higher temperatures the effectiveness is a very non-linear function of doping level. This non-linear behavior corresponds to observations made in operating engines [10-15]. Further, it can be seen that $R_{\text {eff }}$ is much lower around $830 \mathrm{~K}$, where this indicates that $2 \mathrm{EHN}$ is very effective. There are noticeable discrepancies between the experimental and modeling results. Not only do the models over-predict the reactivity of the undoped fuels, but the enhancement due to $2 \mathrm{EHN}$ is excessive. It should be noted however, that the general curvature of the model trends seems to be similar to the experimental measurements, e.g., the peak in $R_{\text {eff }}$ near $740 \mathrm{~K}$ with lower values at higher and lower temperatures. Finally, it is seen that the detailed nitrogen chemistry is predicted to be important only at the higher doping levels. This feature is discussed more in Section 4.2

Figure 5 illustrates the influence of fuel-specific interactions by plotting the ratio of $R_{\text {eff }}$ for TRF91 to $R_{\text {eff }}$ for PRF91 fuel. Here, values greater 1.0 indicate that 2EHN is more effective in the non-aromatic fuel, while values less than 1.0 indicate that $2 \mathrm{EHN}$ is more effective in the aromatic fuel. It can be seen that across most of the temperature range, the experiments indicate that the relative effectiveness is close to 1.0, i.e., $\pm 15 \%$, though at low temperatures and high doping levels $2 \mathrm{EHN}$ is more effective in the TRF91 mixture. At high temperatures, T > $900 \mathrm{~K}, 2 \mathrm{EHN}$ is more effective in the TRF91 mixture, but only at the lowest doping level. The two models on the other hand, indicate that $2 \mathrm{EHN}$ is markedly more effective in the non-aromatic mixture covering most of the NTC regime.

\subsection{Sensitivity analysis}

A summary of the sensitivity analysis is reviewed here while the individual $S_{i}^{\prime}$ s are provided in the Supplementary Material. The top 20 reactions for all of the conditions investigated are listed there, with these designated at times during the simulation where the temperature is computed to rise by $\Delta \mathrm{T}=25,100$ and $800 \mathrm{~K}$ relative to the initial condition. These give an indication of which reactions are sensitive during the early, intermediate and later stages of the ignition process. Note that at $T=684 \mathrm{~K}$, the nominal temperature rise from 
the $1^{\text {st }}$ stage ignition for the undoped mixtures is approximately $\Delta \mathrm{T}=150 \mathrm{~K}$; at $\mathrm{T}=836 \mathrm{~K}$ there is no defined $1^{\text {st }}$ stage ignition for the undoped mixtures.

Simulation results using the unperturbed LLNL mechanism at the nominal conditions are discussed first. Figure 6 illustrates computed mole fractions for $\mathrm{CH}_{2} \mathrm{O}, \mathrm{QOOH}$, and $\mathrm{OH}$ as functions of instantaneous temperature for the two temperatures considered. For this analysis all of the QOOH species are included, though the largest fractions are hydroperoxy octyl and hydroperoxy heptyl radicals. Only two PRF91 and two TRF91 mixtures are presented, one which is undoped and the other which is doped at 3.0\%. Note that the PRF91 results are shifted vertically for better visibility, where the start of the calculation is indicated by a horizontal hatched bar (with the data record truncated below $10^{-3} \mathrm{ppm}$ ). Here it is easily seen that the concentrations of these important intermediates are significantly stimulated by the presence of $2 \mathrm{EHN}$, where this particularly occurs during the early stage of the ignition process, i.e., before the temperature rise of $\Delta \mathrm{T}=25$ $\mathrm{K}$ is realized. Further during the ignition process, it can be seen that the species trajectories for the undoped and doped mixtures tend to converge. This behavior seems to indicate that it is primarily the lower temperature chemistry that is perturbed by the fuel additive.

The sensitivity analysis for undoped PRF91 at $\mathrm{T}=684 \mathrm{~K}$ indicates typical sensitivities to $\mathrm{RH}+\mathrm{OH}=\mathrm{R}+\mathrm{H}_{2} \mathrm{O}$ and $\mathrm{RO}_{2}=\mathrm{QOOH}$ at the early time, additionally to $\mathrm{O}_{2} \mathrm{QOOH}=\mathrm{KETO}+\mathrm{OH}$ at the intermediate time, and $\mathrm{H}_{2} \mathrm{O}_{2}, \mathrm{CH}_{2} \mathrm{O}$, $\mathrm{HCO}$ and $\mathrm{CH}_{3} \mathrm{O}_{2}$ relevant reactions at the later time. At $\mathrm{T}=836 \mathrm{~K}, \mathrm{RH}+\mathrm{HO}_{2}=\mathrm{R}+\mathrm{H}_{2} \mathrm{O}_{2}$ becomes important at all times, as do reactions involving $\mathrm{H}_{2} \mathrm{O}_{2} . \mathrm{CH}_{2} \mathrm{O}$ and $\mathrm{CH}_{3} \mathrm{O}_{2}$ chemistry are somewhat less important. As the fuel is doped at $\mathrm{T}=684 \mathrm{~K}, 2 \mathrm{EHN}$ decomposition becomes important, but only during the early stage. Reactions involving the $\mathrm{C}_{7} \mathrm{H}_{15}-3$ radical, e.g., $\mathrm{R}+\mathrm{O}_{2}=\mathrm{RO}_{2}$ and $\mathrm{RO}_{2}=\mathrm{QOOH}$, etc., also become important, but again only at the early time. On the other hand, reactions involving $\mathrm{CH}_{2} \mathrm{O}$ and $\mathrm{CH}_{3} \mathrm{O}_{2}$ become very important at all times. Only for 3.0\% 2EHN, $\mathrm{NO}_{2}+\mathrm{OH}=\mathrm{HONO}_{2}$ becomes significant, but also just at the early time. At $\mathrm{T}=836 \mathrm{~K}$, the doped mixture indicates increasing sensitivity to again, the $\mathrm{C}_{7} \mathrm{H}_{15}-3$ related reactions, but at this condition these are important throughout the ignition period. There is little sensitivity to the $2 \mathrm{EHN}$ decomposition since it is quite rapid at this temperature. However, $\mathrm{CH}_{2} \mathrm{O}$ and $\mathrm{CH}_{3} \mathrm{O}_{2}$ reactions are again sensitized by the addition of $2 \mathrm{EHN}$. At 
$\mathrm{T}=836 \mathrm{~K}, \mathrm{CH}_{3} \mathrm{NO}_{2}=\mathrm{CH}_{3}+\mathrm{NO}_{2}$ is the only nitrogen-relevant reaction that is sensitive, where this influence seems to be only at early times.

The analysis for undoped TRF91 at $\mathrm{T}=684 \mathrm{~K}$ shows nearly identical results to undoped PRF91, except with the addition of toluene-specific reactions. At $\mathrm{T}=836 \mathrm{~K}$, the results are very similar to undoped PRF91, however the isomerization of 3-heptyl-peroxy radicals to hydroperoxy 3-heptyl radical $(\mathrm{QOOH})$ is found to be influential at all times. As the fuel is doped at $\mathrm{T}=684 \mathrm{~K}$, the sensitive reactions are again very similar to the doped PRF91 blends. This finding corresponds to the trends seen in Fig. 5 where the predicted ratios of $R_{\text {eff }} s$ are close to 1.0. At $\mathrm{T}=836 \mathrm{~K}$ some differences between the fuels become apparent in the model. The aromatic fuel is more sensitive to the dopant-derived 3-heptyl radical reactions, and these sensitivities are consistent across all times during the ignition process. $\mathrm{CH}_{2} \mathrm{O}$ chemistry is slightly less important for the doped TRF91 at this higher temperature. Finally, $\mathrm{NO}+\mathrm{HO}_{2}=\mathrm{NO}_{2}+\mathrm{OH}$ is the only $\mathrm{NOx}$ relevant reaction observed to be important, but just at the highest doping level.

\subsection{Rate of production analysis}

A summary of the ROP analysis is reviewed here while the individual results are provided in the Supplementary Material. This analysis is undertaken in order to understand differences between predictions

using the detailed and skeletal NOx mechanisms, therefore the fate of $\mathrm{NO}_{2}$ is considered. Simulations are conducted at $\mathrm{T}=684 \mathrm{~K}$ for the two fuel blends at a doping level of $3 \%$ with results analyzed at $\Delta \mathrm{T}=25 \mathrm{~K}$, in a manner similar to the sensitivity analysis.

The ROP results indicate that for the skeletal mechanism, the primary pathways for production and consumption are $\mathrm{NO}+\mathrm{HO}_{2}=\mathrm{NO}_{2}+\mathrm{OH}$ and $\mathrm{NO}_{2}+\mathrm{H}=\mathrm{NO}+\mathrm{OH}$, respectively, where this ' $\mathrm{NO}-\mathrm{NO} 2$ loop' can generate substantial amounts of $\mathrm{OH}$. The detailed mechanism however, exhibits more complex interactions where methyl and ethyl nitrite, and nitric acid formation consume $\mathrm{NO}_{2}$, while $\mathrm{R}+\mathrm{NO}_{2}=\mathrm{RO}+\mathrm{NO}$ and $\mathrm{RO}_{2}+\mathrm{NO}=\mathrm{RO}+\mathrm{NO}_{2}$ are substantial consumers and producers of $\mathrm{NO}_{2}$, respectively. These additional reactions significantly compete with 
the $\mathrm{NO}-\mathrm{NO} 2$ loop so that less $\mathrm{OH}$ is generated in the detailed mechanism, and this constrains the reactivity enhancement at the highest doping level.

\subsection{Conclusions}

Experiments and modeling are conducted to investigate the autoignition behavior of two gasoline surrogates doped with $2 \mathrm{EHN}$ to better understand dopant interactions with non-aromatic and aromatic fuels, including accelerating kinetic pathways and enhanced exothermicity. RCM experiments are conducted at $\phi=1$, $\mathrm{Pc}=21 \mathrm{bar}, \mathrm{O}_{2}=11.4 \%$ and $\mathrm{Tc}=650-1025 \mathrm{~K}$ with doping levels of $0.0,0.1,1.0$ and $3.0 \%$. The results indicate that the doping effectiveness of $2 \mathrm{EHN}$ is fairly similar between the two simple surrogates studied here, where minor influences are observed at the lowest temperatures, while at higher temperatures, i.e., in the NTC regime, the influence is large and very non-linear with doping level. 2EHN seems to be is slightly more effective in the aromatic blend at the lower temperatures, but somewhat more effective in the non-aromatic blend at intermediate temperatures. Very little change is observed in the exothermicity of ignition, e.g., the extents of heat release during the $1^{\text {st }}$ stage of ignition, however more investigation of this is warranted, especially since $\mathrm{CH}_{3} \mathrm{O}_{2}$ has been identified as influential towards intermediate temperature heat release (ITHR) in $\mathrm{HCCl}$ engines. Investigations using other aromatics, including polycyclic structures would be informative.

Kinetic modeling indicates that although some of the reactivity trends can be captured using a detailed model, the extents of predicted cetane enhancement are too large, while the differences in fuel interactions between the two fuels lead to excessive stimulation of the non-aromatic blend. The model indicates that the $\mathrm{CH}_{2} \mathrm{O}$ and $\mathrm{CH}_{3} \mathrm{O}_{2}$ chemistry are very sensitive to the dopant at all conditions, while $2 \mathrm{EHN}$ decomposition only seems to be sensitive at low temperatures where its decomposition rate is slower due to the high activation energy of the reaction ( $40 \mathrm{kcal} / \mathrm{mole}$ ). At higher temperatures, dopant-derived 3-heptyl radicals are predicted to play an important role stimulating ignition, and nitrogen chemistry becomes important only at the highest doping levels, primarily through the formation of methyl nitrite and nitric acid. The formation of methyl and 
ethyl nitrite, as well as nitric acid are predicted to compete with the 'NO - NO2 loop' where this reduces the production of $\mathrm{OH}$, and thereby constrains the effectiveness of $2 \mathrm{EHN}$.

This study helps to improve the fundamental understanding of alkyl nitrate additives at engine-relevant conditions, where this can lead to more sophisticated models which may give better agreement with experimental measurements and be useful in engine simulations.

\section{Acknowledgements}

Timothy Smith and Steve McConnell (ANL) helped maintain and operate the RCM. Funding at ANL and LLNL for this work was provided by the US DOE Vehicle Technology Program with Gurpreet Singh as program manager. This manuscript has been created in part by UChicago Argonne, LLC, Operator of Argonne National Laboratory ("Argonne"). Argonne, a U.S. Department of Energy Office of Science laboratory, is operated under Contract No. DE-AC02-06CH11357. The LLNL work was performed under the auspices of the US Department of Energy by Lawrence Livermore National Laboratory under Contract DE-AC52-07NA27344. The U.S. Government retains for itself, and others acting on its behalf, a paid-up non-exclusive, irrevocable worldwide license in said article to reproduce, prepare derivative works, distribute copies to the public, and perform publicly and display publicly, by or on behalf of the Government. 


\section{References}

[1] Y. Yang, J. Dec, N. Dronniou, W. Cannella, SAE Paper 2012-01-1120, 2012.

[2] S.L. Kokjohn, R.M. Hanson, D.A. Splitter and R.D. Reitz, SAE Paper 2009-01-2647, 2009.

[3] G.J. Suppes, Y. Rui, A.C. Rome and Z. Chen, Ind. Eng. Chem. Res. 36 (1997) 4397-4404.

[4] T. Inomata, J.F. Griffiths, A.J. Pappin, $23^{\text {rd }}$ Symp. (Int.) Combust. (1990) 1759-1766.

[5] J.F. Griffiths, Q. Jiao, W. Kordylewski, M. Schreiber, J. Meyer, and K.F. Knoche, Combust. Flame 93 (1993) 303-315.

[6] S. Tanaka, F. Ayala, J.C. Keck and J.B. Heywood, Combust. Flame 132 (2003) 219-239.

[7] A. Toland, J.M. Simmie, Combust. Flame 132 (2003) 556-564.

[8] M. Hartmann, K. Tian, C. Hofrath, M. Fikri, A. Schubert, et al., Proc. Comb. Inst. 32 (2009) 197-204.

[9] Y. Stein, R.A. Yetter, F.L. Dryer and A. Aradi, SAE Paper 1999-01-1504, 1999.

[10] P.Q.E. Clothier, S.M. Heck and H.O. Pritchard, Combust. Flame 121 (2000) 689-694.

[11] A.M. Ickes, S.V. Bohac and D.N. Assanis, Energy Fuels 23 (2009) 4943-4948.

[12] C.P. Kolodziej, S. Ciatti, D. Vuilleumier, B.D. Adhikery, R. Reitz, SAE Paper 2014-1-1302, 2014.

[13] J.A. Eng, W.R. Leppard and T.M. Sloane, SAE Paper 2003-01-3179, 2003.

[14] R. Hanson, S. Kokjohn, D. Splitter, R. Reitz, SAE Paper 2011-01-0361, 2011.

[15] J. Kaddatz, M. Andrie, R. Reitz, S. Kokjohn, SAE Paper 2012-01-1110, 2012.

[16] W.-T. Chan, S.M. Heck and H.O. Pritchard, Phys. Chem. Chem. Phys. 3 (2001) 56-62.

[17] H. Bornemann, F. Scheidt and W. Sander, Int. J. Chem. Kinet. 34 (2002) 34-38.

[18] S.S. Goldsborough et al., in preparation for Combustion and Flame.

[19] M. Mehl, W.J. Pitz, C.K. Westbrook, H.J. Curran, Proc. Comb. Inst. 33 (2011) 193-200.

[20] G. Kukkadapu, K. Kumar, C.-J. Sung, M. Mehl, W.J. Pitz, Combust. Flame 159 (2012) 3066-3078.

[21] G. Kukkadapu, K. Kumar, C.-J. Sung, M. Mehl, W.J. Pitz, Proc. Comb. Inst. 34 (2013) 345-352.

[22] http://www.me.berkeley.edu/gri_mech/version30/text30.html

[23] P. Dagaut, F. Lecomte, S. Chevailler and M. Cathonnet, Combust. Sci. Tech. 148 (1999) 27-57. 
[24] P. Dagaut and A. Nicolle, Combust. Flame 140 (2005) 161-171.

[25] G. Moreac, P. Dagaut, J.F. Roesler and M. Cathonnet, Combust. Flame 145 (2006) 512-520.

[26] P. Dagaut, P. Glarborg and M.U. Alzueta, Prog. Energy Combust. Sci. 34 (2008) 1-46.

[27] C.L. Rasmussen, J. Hansen, P. Marshall and P. Glarborg, Int. J. Chem. Kinet. 40 (2008) 454-480.

[28] C.L. Rasmussen, A.E. Rasmussen and P. Glarborg, Combust. Flame 154 (2008) 529-545.

[29] T. Faravelli, A. Frassoldati and E. Ranzi, Combust. Flame 132 (2003) 188-207.

[30] J.M. Anderlohr, R. Bounaceur, A. Pires Da Cruz and F. Battin-Leclerc, Combust. Flame 156 (2009) 505521.

[31] C.V. Naik, K. Puduppakkam and E. Meeks, SAE Paper 2010-01-1084, 2010.

[32] E.R. Ritter and J.W. Bozzelli, Int. J. Chem. Kinet. 23 (1991) 767-778.

[33] D. Darcy, H. Nakamura, C.J. Tobin, M. Mehl, W.K. Metcalfe, W.J. Pitz, C.K. Westbrook, Combust. Flame $161(2014) 65-74$.

[34] S.S. Goldsborough, G. Mittal, C. Banyon, Proc. Comb. Inst. 34 (2013) 685-693.

[35] D.D.Y. Zhou, M.J. Davis, R.T. Skodje, J. Phys. Chem. A 117 (2013) 3569-3584.

[36] S.S. Goldsborough, D.Longman, M.S. Wooldridge, R.S. Tranter, S. Pratt, http://www.transportation.anl.gov/rcmworkshop 


\section{Figures}

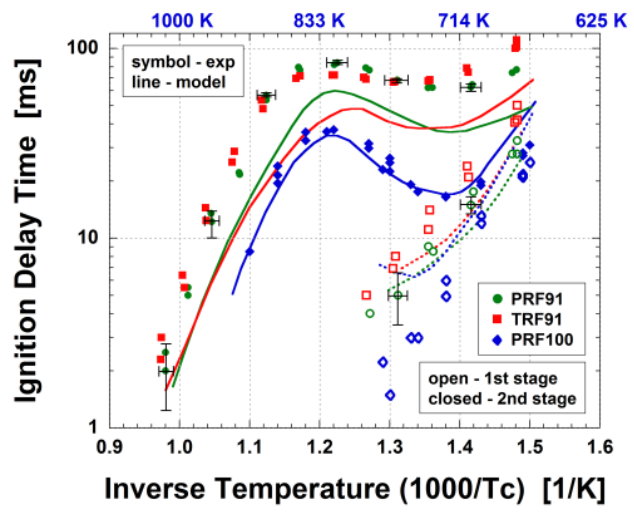

Figure 1 - Ignition delay times as function of temperature for three undoped fuels.

Image:

$53 \mathrm{~mm}$ tall $\times 67 \mathrm{~mm}$ wide

$(53+10) \times 2.2 \mathrm{word} / \mathrm{mm}=139$ words

Caption: 13 words 


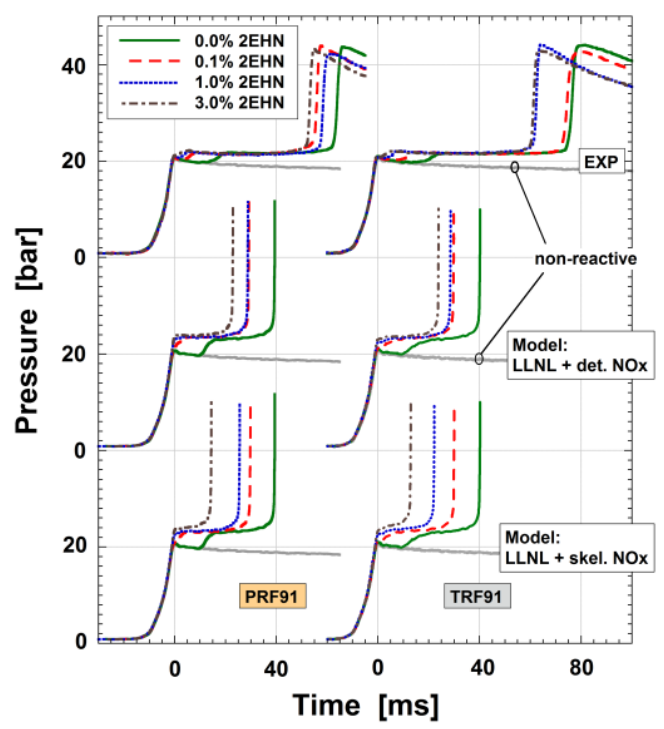

Figure $\mathbf{2}$ - Representative experimental and simulated pressures as functions of time for Tc $=710 \mathrm{~K}$.

Image:

$74 \mathrm{~mm}$ tall $\times 67 \mathrm{~mm}$ wide

$(74+10) \times 2.2 \mathrm{word} / \mathrm{mm}=185$ words

\section{Caption: 16 words}




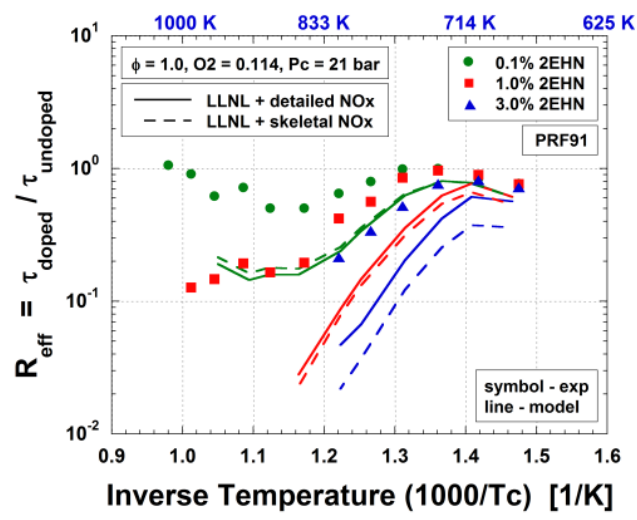

Figure 3 - Effectiveness ratio as function of temperature for PRF91 mixes.

Image:

$53 \mathrm{~mm}$ tall $\times 67 \mathrm{~mm}$ wide

$(53+10) \times 2.2 \mathrm{word} / \mathrm{mm}=139$ words

Caption: 11 words 


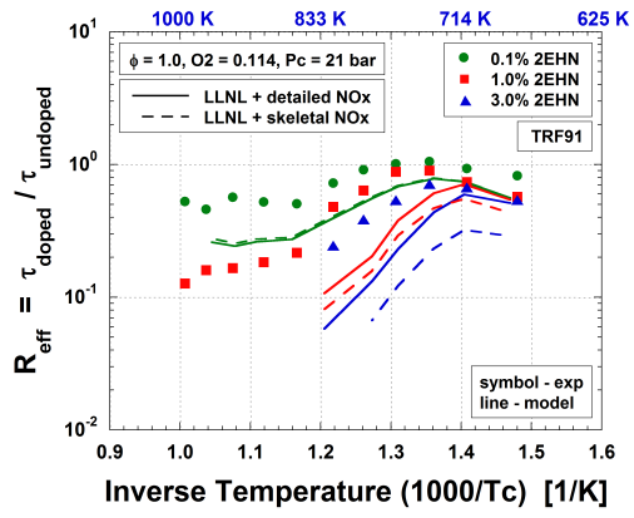

Figure 4 - Effectiveness ratio as function of temperature for TRF91 mixes.

Image:

$53 \mathrm{~mm}$ tall $\times 67 \mathrm{~mm}$ wide

$(53+10) \times 2.2 \mathrm{word} / \mathrm{mm}=139$ words

Caption: 11 words 


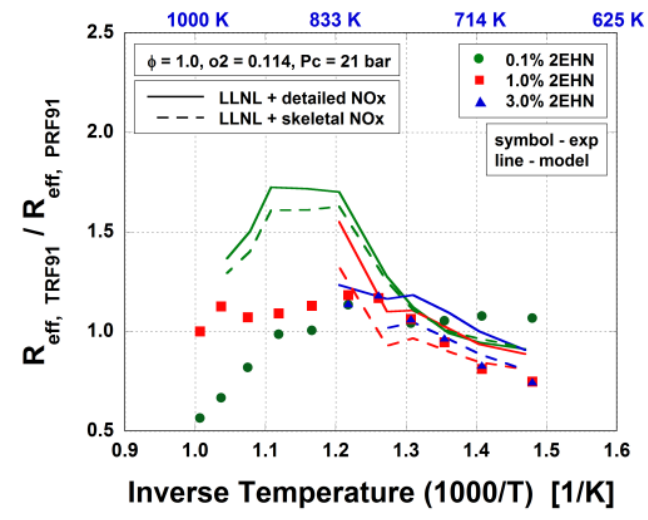

Figure 5 - Relative doping effectiveness as function of temperature.

Image:

$53 \mathrm{~mm}$ tall $\times 67 \mathrm{~mm}$ wide

$(53+10) \times 2.2 \mathrm{word} / \mathrm{mm}=139$ words

\section{Caption: 9 words}




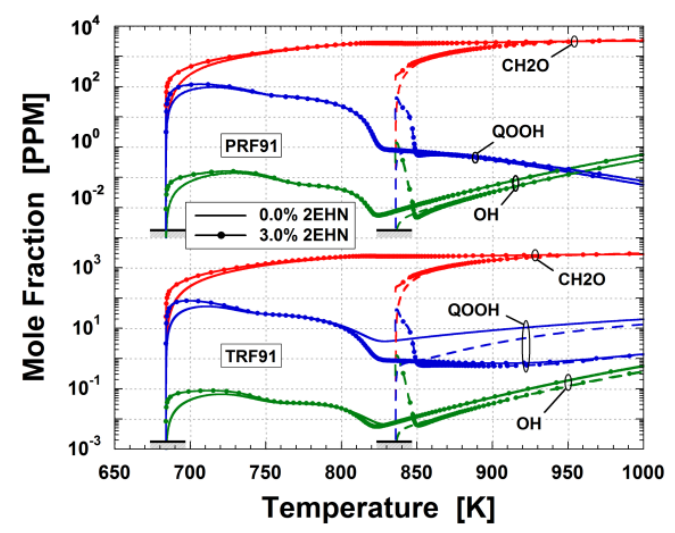

Figure 6 - Mole fractions of $\mathrm{CH}_{2} \mathrm{O}, \mathrm{QOOH}$ AND OH as functions of temperature for undoped (lines) and 3.0\% doped (lines + symbols) mixtures at two constant volume conditions, $\mathrm{Ti}=684 \mathrm{~K}$ (solid) and $\mathrm{Ti}=836 \mathrm{~K}$ (dashed).

Image:

$53 \mathrm{~mm}$ tall $\times 67 \mathrm{~mm}$ wide

$(53+10) \times 2.2 \mathrm{word} / \mathrm{mm}=139$ words

\section{Caption: 39 words}




\section{Figure Captions}

Figure 1 - Ignition delay times as function of temperature for three undoped fuels.

Figure 2 - Representative experimental and simulated pressures as functions of time for Tc $=710 \mathrm{~K}$.

Figure 3 - Effectiveness ratio as function of temperature for PRF91 mixes.

Figure 4 - Effectiveness ratio as function of temperature for TRF91 mixes.

Figure 5 - Relative doping effectiveness as function of temperature.

Figure 6 - Mole fractions of $\mathrm{CH}_{2} \mathrm{O}, \mathrm{QOOH}$ AND OH as functions of temperature for undoped (lines) and $3.0 \%$ doped (lines + symbols) mixtures at two constant volume conditions, $\mathrm{Ti}=684 \mathrm{~K}$ (solid) and $\mathrm{Ti}=836 \mathrm{~K}$ (dashed). 